DOI 10.37882/2223-2982.2021.08.37

\title{
СТРУКТУРА СЕМАНТИЧЕСКОГО ПОЛЯ «АЛКОГОЛЬНОЕ ОПЬЯНЕНИЕ» НА МАТЕРИАЛЕ АНГЛИЙСКОГО ЯЗЫКА
}

\section{THE STRUCTURE OF THE SEMANTIC FIELD "ALCOHOLIC INTOXICATION" ON THE MATERIAL OF THE ENGLISH LANGUAGE}

M. Urazaev

Summary: This article attempts to analyze paradigmatic relations within the framework of the studied elements of the field «alcoholic intoxication» on the material of the English language. The reflection of the dialectical unity of statics and dynamics in lexical and semantic fields is proved.

Keywords: lexico-semantic field, concept, lexico-semantic group, paradigmatic relations, field feature.
Уразаев Марат Дамирович

Аспирант, Башкирский государственный университет marat-urazaev@yandex.ru

Аннотация: В данной статье производится попытка анализа парадигматических отношений в рамках исследуемых элементов поля «алкогольное опьянение» на материале английского языка. Доказывается отражение диалектического единства статики и динамики в лексико-семантических полях.

Ключевые слова: лексико-семантическое поле, концепт, лексико-семантическая группа, парадигматические отношения, полевый признак.

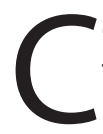

емантические поля представляют большой интерес для лингвистов. Полевой подход является плодотворным при описании языковых явлений, так как он помогает определить системную организацию языка. Первоначально идея полевой организации связей между языковыми явлениями была разработана применительно к лексическому составу языка в трудах немецких ученых (Г. Ипсен, Й. Трир, В. Порциг и др.). Затем она была переосмыслена в общий принцип строения языковой системы.

Проблема полевой концепции волновало, как зарубежных, так и отечественных исследователей. Работы, посвященные описанию поля в области лингвистики, связаны с такими именами, как Г.Г. Сильницкий, И.В. Арнольд, Н.И. Филичева, О.Г. Ревзина, О.С. Ахманова, И.И. Чумак и многих других. Проанализировав труды ученых, мы выявили то, что родоначальники теории поля не были схожи в своих взглядах. С современной точки зрения в их работах много спорных моментов, и они неоднократно подвергались критике, но полевой подход, несомненно, стал новым этапом в исследовании языка и словарного состава.

Семантическое поле есть не только методологически наиболее важная метаязыковая единица, но и наиболее психологически реальная для человека единица мышления. Лексические структуры разных видов могут сочетаться в пределах общего семантического поля, которое представляет собой информационное целое, объединяющее лексические единицы с инвариантным значением. Вследствие этого соответствующее понятие может служить метаязыковой универсалией (эталоном) в сравни- тельных исследованиях по лексической семантике [6].

Целью нашего исследования является анализ структуры лексико-семантического поля «алкогольного опьянения» на материале английского языка.

Для достижения цели были поставлены следующие задачи:

- Провести концептуальный анализ понятия «алкогольное опьянение в английском языке».

- Выявить и классифицировать лексические единицы, связанные с обозначением семантического поля «алкогольное опьянение».

- Описать на основе выявленных элементов структуру семантического поля «алкогольного опьянения».

Актуальность исследования объясняется подвижностью и открытостью лексического состава. Лексическая система прямо или косвенно отражает действительность, реагирует на изменения в общественной, материальной и культурной жизни народа, пополняется новыми словами для обозначения новых предметов, явлений, процессов, понятий. Все это свидетельствует о перспективном характере изучения динамики семантических полей.

Материал данного исследования составили 132 лексемы, отобранных методом сплошной выборки из словаря Longman Dictionary of Contemporary English, раскрывающие особенности восприятия алкогольного опьянения в английском языке [7].

Основными методами исследования являются: ком- 
понентный анализ; контрастивный анализ; количественный анализ.

В современной лингвистике полевой подход к описанию языковых явлений получил широкое распространение. Исследуются как отдельные языковые поля, так и полевой характер в целом. К главным положениям полевой концепции языка относятся:

1. Поле - это совокупность элементов, связанных между собой системными отношениями.

2. Элементы, входящие в состав поля, связаны семантически и выполняют в языке единую функцию.

3. Элементы в поле могут быть как однородными, так и разнородными.

4. Поле образуется из некоторых составных частей - микрополей. Число микрополей должно быть не меньше двух.

5. Организация полей может быть вертикальной и горизонтальной. Вертикальная организация структура микрополей, а горизонтальная - их взаимоотношение.

6. В составе поля выделяются: ядро и периферийные конституенты. Ядро, в свою очередь, консолидируется вокруг составляющей-доминанты.

7. Ядро выполняет однозначные функции и обязательны для конкретного поля.

8. Выполняемые полем функции распределяются между ядром поля и его периферией. При этом часть функций распространяется на ядро, часть на периферию.

9. Граница между яром и периферией не является четкой.

10. Конституенты поля могут относиться к ядру одного поля и периферии другого поля.

11.Законом полевой организации системы полей является то, что равные поля накладываются друг на друга, образуя при этом зоны постепенных переходов.

В лингвистике выделяют несколько видов полей.

О. Духачек выделяет два основных вида полей: словесные лингвистические поля, ядром который является слово, и понятийные лингвистические поля. Словесные поля Е. Диброва разделяет на синтаксические, морфологические и ассоциативные.

В концепции Н.И. Филичевой синтаксическое поле представлено как группировка синтаксических моделей. Формирование структурных моделей в синтаксические поля видится автором в том, что между этими структурными моделями существуют функциональные и семантические связи, в которых прослеживаются связи между соответствующим отношениями объективной реальности [3].
В концепции поля М.М. Гухман мы находим понятие грамматического поля, обладающего центром и периферией. Автор считает, что в отличие от грамматической категории, поле представляет собой структуру, включающую единицы, которые находятся на границе парадигматики и синтагматики, образуя при этом периферийную зону поля. Выделяют также и ассоциативные поля. Любое ассоциативное поле имеет ядро, центр и периферию. Ядро данного поля состоит из неоднократно повторяющихся ассоциаций, более значимых ассоциаций. Исследователи высказывают мысль о том, что хотя бы дважды повторяющаяся ассоциация не случайна. Менее частотные ассоциации отходят к периферийной зоне поля [4].

Как было сказано выше, одна из функций слов - обозначать вещи, понятия и так далее. Пользователи языка не могут иметь никаких знаний или мысли об объектах или явлениях реального мира вокруг них, если это знание в конечном итоге не воплощается в словах, которые имеют, по существу, одинаковое значение для всех носителей этого языка. Это денотационное значение, то есть тот компонент лексического значения, который делает возможным общение. Нет сомнений в том, что физик знает об атоме больше, чем певец, или что исследователь Арктики обладает гораздо более глубокими знаниями о том, что такое арктический лед, чем человек, который никогда не был на Севере. Тем не менее они используют слова атом, Арктика и т.д. И понимают друг друга.

Второй компонент лексического значения - это коннотационный компонент, т. е. Эмоциональный заряд и стилистическая ценность слова.

Слова содержат элемент эмоциональной оценки как часть коннотационного значения; например, лачуга означает «маленький дом или коттедж» и, кроме того, подразумевает, что это жалкое жилище, грязное, в плохом ремонте и в целом неприятное для жизни. При изучении синонимов большой, большой, огромный и подобные, любовь, поклонение или такие слова, как девушка, девушка; дорогая, дорогая, мы не можем не заметить разницу в эмоциональном заряде членов этих множеств. Эмоциональный заряд слов огромный, поклонение и девчушка тяжелее, чем у слов большой, вроде и девочка. Это не зависит от «ощущений» отдельного говорящего, но верно для всех носителей английского языка. Эмоциональный заряд варьируется в разных классах слов. В некоторых из них, например, в междометиях преобладает эмоциональный элемент,

Эмоциональный заряд является одним из объективных семантических признаков, свойственных слова, как языковые единиц и формы части коннотативной компоненты значения. Его не следует путать с эмоциональным подтекстом, который слова могут приобретать 
в речи. Эмоциональный смысл слова в значительной степени субъективен, поскольку он во многом зависит от личного опыта говорящего, ментальных образов, которые слово вызывает в нем. Слова, кажущиеся лишенными какого-либо эмоционального элемента, могут обладать в случае отдельных говорящих сильным эмоциональным подтекстом, что можно проиллюстрировать, например, словом, больница. То, что думают и чувствуют, когда используется слово «больница», будет другим в случае архитектора, который ее построил, инвалида, оставшегося там после операции, или человека, живущего через дорогу.

В настоящей статье мы будем рассматривать лексикосемантическое поле (далее ЛСП) «алкогольное опьянение» на материале английского языка. Следует отметить, что алкогольная лексика преимущественно принадлежит разговорной разновидности английского языка и просторечию, отличается повышенной стилистической и эмоционально-оценочной окрашенностью [1]

Построение ЛСП проходило в несколько этапов. Первым из них является: концептуальный анализ. Мы исходим из того, что группировка лексико-семантического поля происходит вокруг концепта, а соответствующее слово-концепт, номинирующее ядро описываемого концепта, является именем поля [5]. Языковая картина мира репрезентирует концептуальную картину мира, которая в свою очередь представляет собой репрезентант реального объективного мира. Мы исходим их того, что группировка лексико-семантического поля происходит вокруг концепта, а соответствующее словоконцепт, номинирующее ядро описываемого концепта, является именем поля. Следует отметить, что концепт «alcoholic intoxication» имеет полевую структуру и представлен в языке лексико-семантическим полем «alcoholic intoxication», состоящим из микрополей.

Таким образом, концепт «alcoholic intoxication» связан и со смежными концептами, которые влияют друг на друга и дополняют друг друга, образуя концептуальную картину мира. В результате мы получили набор лексем, имеющих ассоциативное отношение к лексеме «alcohol». Далее был проведен компонентный анализ с целью разложения значения каждой из лексем на минимальные семантические составляющие и вычленения общих признаков.

Метод компонентного анализа - метод исследования содержательной стороны значимых единиц языка. Он опирается на идею системно-парадигматического устройства языка, являясь результатом перенесения принципов анализа из фонологии в семантику и грамматику. Для настоящего исследования был проведен компонентный анализ наименований лексико-семантического поля «alcoholic intoxication».
Проведем компонентный анализ лексемы «alcoholic intoxication». Так как мы имеем дело, по факту, с двумя единицами, из которых складывается значение слова, то обратимся к словарю Merriam - Webster, где находим определение слов.

a: the condition of having physical or mental control markedly diminished by the effects of alcohol or drugs drank to the point of intoxication cocaine intoxication

b: a strong excitement or elation the mere knowledge that they are on an island, a little world entirely surrounded by the sea, fills them with an indescribable intoxication ...-Christine Osborne.

2: an abnormal state that is essentially a poisoning carbon monoxide intoxication

И для единицы alcohol.

a: ethanol especially when considered as the intoxicating agent in fermented and distilled liquors.

b: drink (such as whiskey or beer) containing ethanol.

c: a mixture of ethanol and water that is usually 95 percent ethanol.

2: any of a class of organic (see ORGANIC entry 1 sense $1 b$ (2)) compounds that are analogous to ethanol and that are hydroxyl derivatives of hydrocarbons

Представим схему значений следующим образом:

$$
\mathrm{A}+\mathrm{S}_{1}+\mathrm{S}_{2}+\mathrm{S}_{3}
$$

Следующим представим компонентный анализ лексемы «alcoholic intoxication»:

Alcohol intoxication, also known as alcohol poisoning, commonly described as drunkenness or inebriation, is the negative behavior and physical effects caused by a recent consumption of alcohol. The toxicity aspect of alcohol happens because of the metabolism of alcohol to acetaldehyde, and the associated and resulting biological processes.

$$
\begin{aligned}
& A-\text { Alcohol } \\
& S_{1}-\text { intoxication } \\
& S_{2}-\text { biological processes } \\
& A+S_{1}+S_{2}
\end{aligned}
$$

Мы можем сделать вывод, что из определения нельзя исключить ни алкоголь, как средство отравления, ни интоксикацию, как результат принятия чрезмерного количества, либо принятия некачественного алкоголя, но они не могут быть объединены в одну и ту же лексикосемантическую группу ввиду отсутствия схожих архисем 
и дифференциальных сем.

Проводим метод компонентного анализа далее.

Intoxication is a condition of a person who drinks large amounts of alcohol.

A-alcohol

S1 - (state) clouded consciousness.

S2 - (size) strong to low intoxication

S3 - (behavior) aggressiveness, activity

$\mathrm{A}+\mathrm{S}_{1}+\mathrm{S}_{2}+\mathrm{S}_{3}$

Таким образом, мы можем говорить о том, что архисема алкогольного опьянения реализуется в контексте помутненного сознания и агрессивного или негативного поведения.

Далее метод компонентного анализа был проведен аналогично для всех лексем.

После проведения компонентного анализа всех лексем, имеющих ассоциативное отношение с концептом «Alcohol intoxication», нами были проведены следующие этапы: формировались лексико-семантические группы; рассматривались лексические ряды; рассматривались деривационные ряды; указывалось наличие парадигматических отношений внутри лексико-семантического поля.

Лексико-семантическое поле «Alcohol intoxication» представляет собой семантически соотнесенную группу единиц, включающую в свой состав семантически сходные слова знаменательных частей речи. Все эти слова связаны между собой системными семантическими корреляциями, обозначают различные реалии объективной действительности и объединены общим семантическим признаком «changes in psychological, physiological and behavioral functions of a person». Исследуемое поле интуитивно понятно носителю языка, относительно автономно и обладает для говорящего психологической реальностью. Полученное нами лексико-семантическое поле «alcoholism / alcoholic» реализуется в 27 единицах.

Структура лексико-семантического поля «Alcohol intoxication» достаточно сложна. В ядро данных лексем входят единицы, которые описывают алкогольное опьянение как заболевание. Данная группа относится к активной лексике. Лексика пассивного словарного запаса может быть отнесена к периферийной части поля.

Обратимся к анализу ядерной зоны исследования. Родовой семой или гиперсемой нашего семантического поля выбрана лексема «alcohol abuse», т.к. данная лексема, так или иначе, относится к характеристикам явления и говорит о явлении действительности в контексте описания алкогольного опьянения.
Охарактеризуем лексико-семантические группы в ядре лексико-семантического поля «alcohol abuse». Мы выделили 11 единиц, которые включили в себя 1 группу прилагательных, 1 группу глаголов.

Проанализируем особенности реализации данной группы в следующих значениях «blind drunk », «alcoholism», "chronic alcoholic», "people with alcohol problems», "crack open a bottle», "kill a beer/bottle of wine etc», "drown your sorrows», «drunk and disorderly», «roaring drunk», «harddrinking», «pub-crawl».

Основным критерием для определения ядра лексико-семантического поля, его ближней и дальней периферии послужил принцип частотности и денотативное содержание морфем. При анализе лексикосемантических групп мы будем выделять как периферические, так и ядерные значения. В состав ближней периферии входит 13 лексико-семантических групп, включающих 8 групп существительных, 2 группы прилагательных, 3 группы глаголов. В ближнюю периферию мы включили следующие лексико-семантические группы: «raise your glass», «refresh somebody's drink», «top somebody up», "sot», "stinking drunk», «the hair of the dog (that bit you)», «toss something $\leftrightarrow$ off written», «wrecked / rekt/», «old soak», «barhop», «be out of/off your head», «be well away», «bombed».

Как мы видим, все исследуемые единицы, так или иначе, соотносятся с алкогольной зависимостью. Каждая группа, входящая в лексико-семантическое поле, имеет свои особенности и различия. Все они так или иначе соотносятся с алкогольным опьянением и специфическим поведением, которое этим опьянением обусловлено. На периферии же располагаются единицы с более специализированным значением, менее употребительные, входящие в другие семантические объединения.

Наглядно представим реализацию ядра семантического поля на рисунке 1.

На рисунке 2 представим ближнюю периферию лексико-сематического поля.

Для обобщения информации о специфике лексикосематического поля, представим характеристику лексических рядов. Синонимические ряды можно представить следующим образом:

1. drunkard (noun)

2. dipsomaniac, boozer, spirits, drinker, drunk, addict, alcohol addict, heavy drinker, habitual drunkard.

3. alky (noun)

4. alcohol, alcoholic beverage, alcohol drink, alcoholic drink, alcohol consumption, alcoholism, booze, liquor, spirit, distillery, alcoholic beverages, inveterate, inveterate drunkard. 


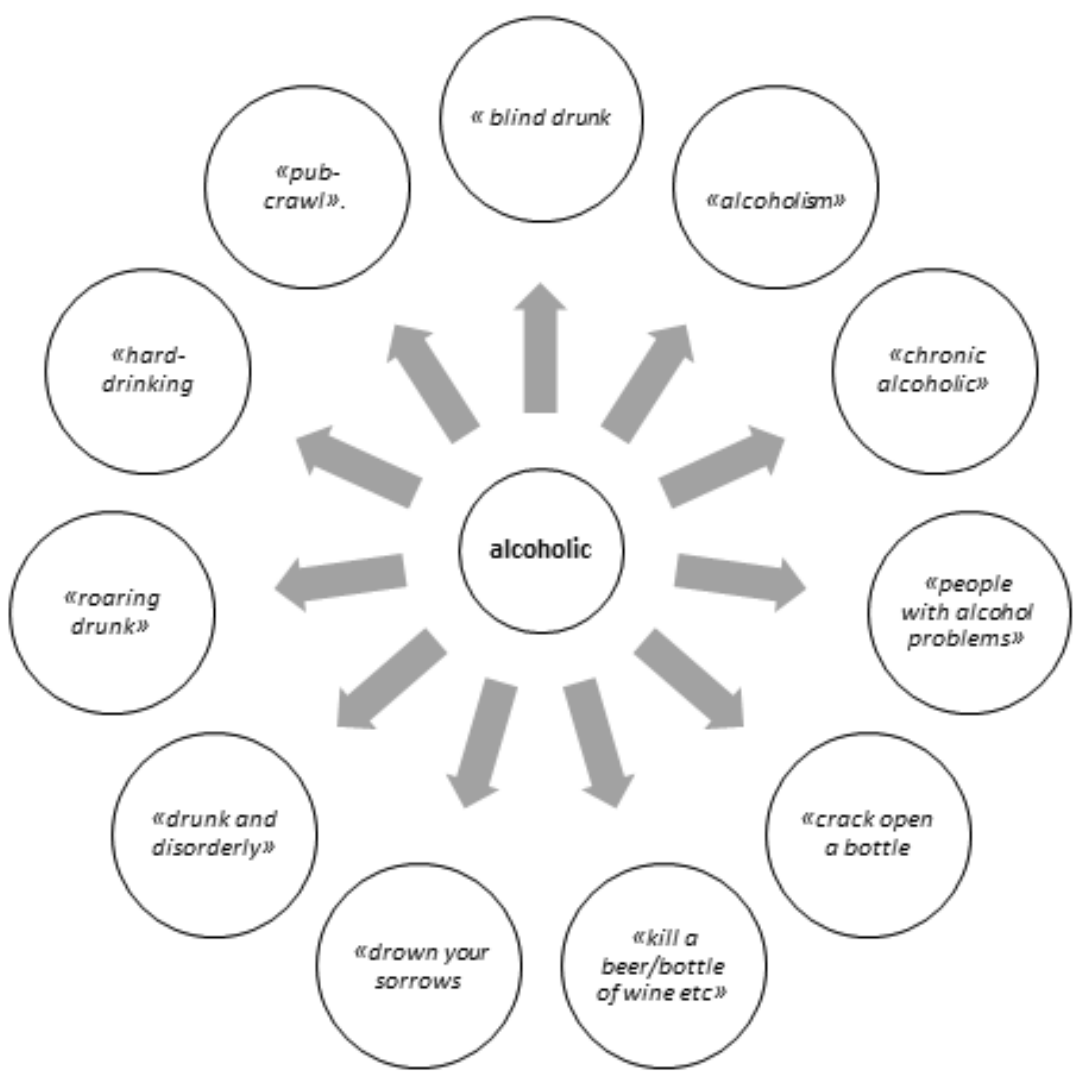

Рис. 1. Ядро лексико-семантического поля

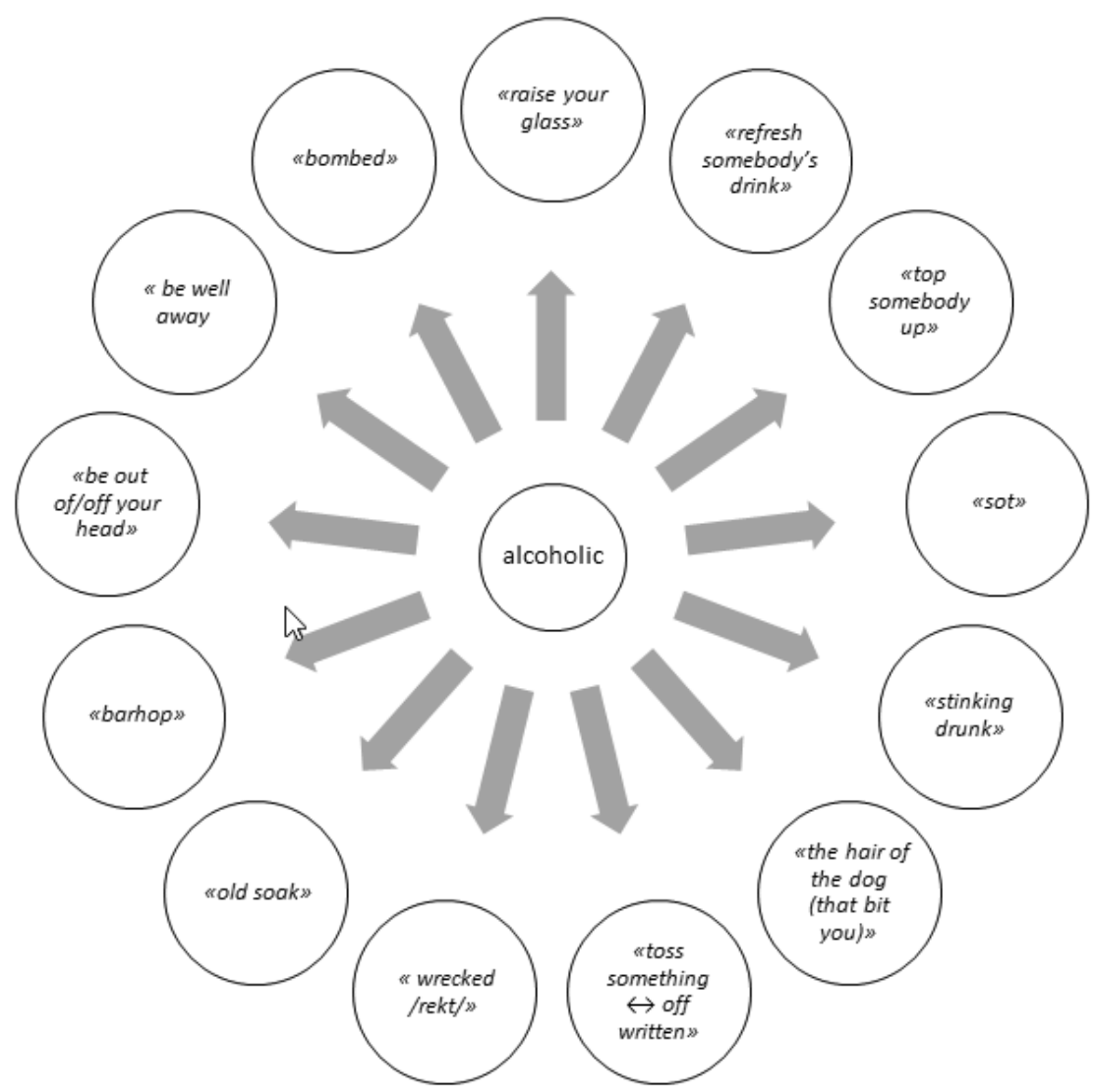

Рис. 2. Периферия лексико-семантического поля 
На следующем этапе нами производился поиск антонимов.

1. alcoholic drink

2. soft drink • nonalcoholic beverage

Таким образом, лексико-семантическое поле, являясь вербализованной формой репрезентации концепта «алкогольное опьянение», с одной сторо- ны, реализовано как динамические образование, которое способно постоянно изменяться. С другой стороны, такое образование позволит раскрыть особенности лексико-семантического поля и представления об алкогольном опьянении среди носителей английского языка. Из этого следует, что лексико-семантические поля, как и структуры других языковых уровней, отражают диалектическое единство статики и динамики.

\section{ЛИТЕРАТУРА}

1. Долгова, Е.Ю. Лексика и фразеология, связанная со сферой употребления спиртных напитков, в русском языке: автореферат дис. ... кандидата филологических наук : 10.02.01 / Долгова Елена Юрьевна; [Место защиты: Башкир. гос. ун-т]. - Самара, 2009. - 21 с.

2. Карасик, В.И. Языковой круг: личность, концепты, дискурс. - М.: Гнозис, 2004. -390 с.

3. Мазаева, М.Ю. Языковая и концептуальная картины мира (к теории вопроса) // Известия высших учебных заведений. Северо-Кавказский регион. Общественные науки. - 2006. - №2. - С. 14-16.

4. Мазинов, А.О. Ганиева // Сопоставительная лингвистика. - 2017. - №6. - С. 41-48.

5. Потапова 0.Е. Вербальная репрезентация концепта. Лексико-семантическое поле как фрагмент языковой картины мира (на материале ЛСП «море»): монография / 0.Е. Потапова. - Чебоксары: ИД «Среда», 2020. - 164 с.

6. Шафиков С.Г. Изучение языковых универсалий с помощью метода семантического поля // Педагогический журнал Башкортостана. 2017. №5 - С. 148 - 153.

7. Longman Dictionary of Contemporary English (Fifth edition). (2009). Harlow: Pearson Education Limited.

(с) Уразаев Марат Дамирович (marat-urazaev@yandex.ru)

Журнал «Современная наука: актуальные проблемы теории и практики»

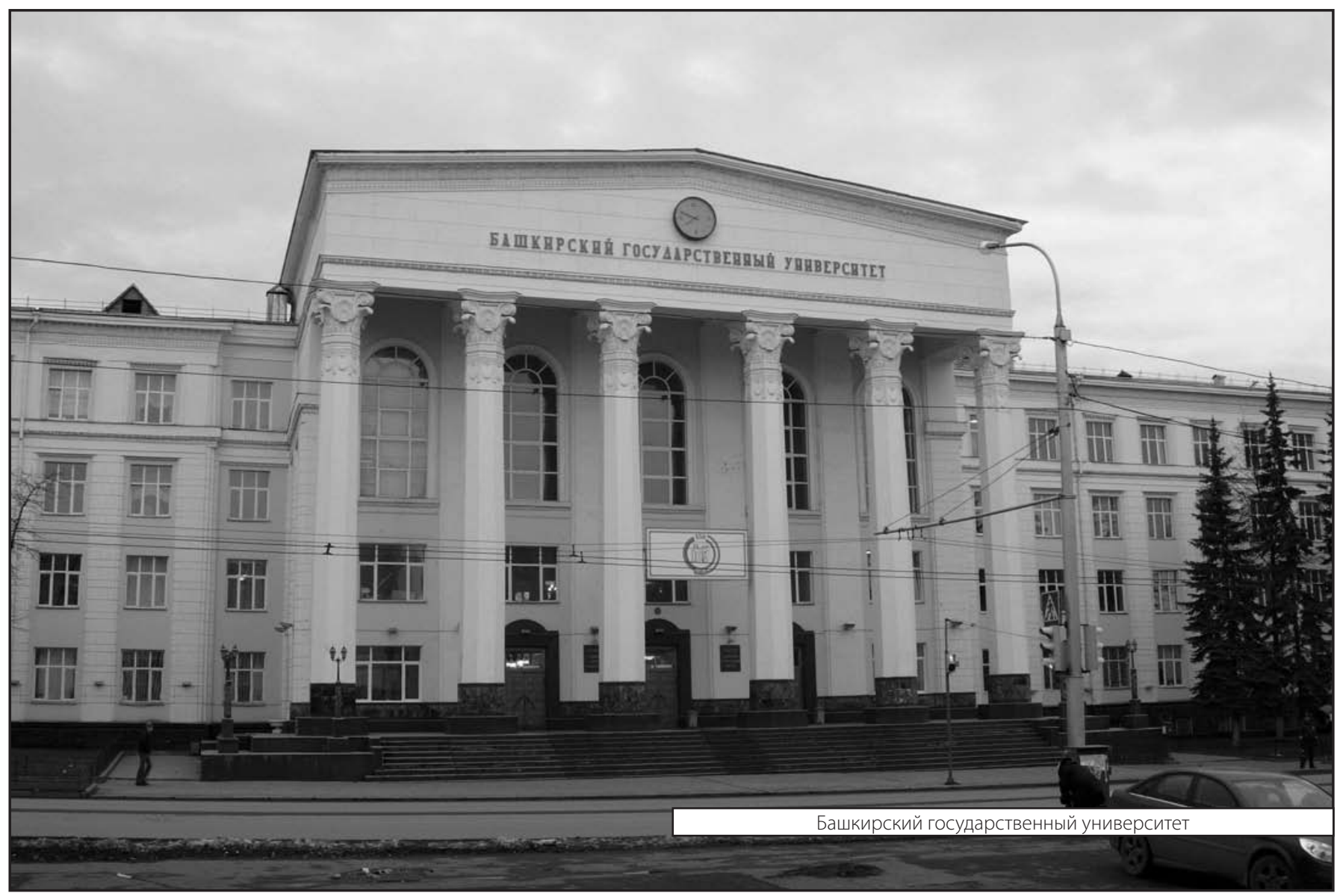

